\title{
Analysis of the Research Status of Solon Tribe Plastic Arts in Heilongjiang River Valley in China and Russia*
}

\author{
Zhongfeng Fu \\ Heihe University \\ Heihe, China
}

\begin{abstract}
In the study of Sino-Russian Heilongjiang River Valley culture, most scholars' researches focus on the study of the history of northern minorities. They only have a general statement about the plastic arts, and there are obvious shortcomings in the depth of theoretical exploration and highlighting academic personality. The previous experts and scholars at home and abroad have compiled a large amount of literature and materials on the research on the national plastic arts, and demonstrated from different angles, there are existing results in both research papers and academic monographs. However, they are mostly limited to the study of individual cases or the research in a particular subject area. The researches deeply excavating the national plastic art from the perspective of aesthetics are scattered, and there is still blank in the art research especially for the local ethnic groups with regional characteristics, namely Solon people in the SinoRussian Heilongjiang River Valley. This research is a preliminary attempt and exploration in this field.
\end{abstract}

Keywords-China and Russia; Heilongjiang River Valley; Solon people; plastic arts

\section{INTRODUCTION}

The so-called valley refers to a water system that never dries. The human groups living in this water system are distributed along the valley of water system and the water system is their lifeline as well as the direction of their migration and movement. Where the water flows, there is their home. The history and culture of Heilongiiang River Valley is originated from this water system, and it also showed the characteristics of the basin culture, which is the characteristic of "sacrificing water and worshipping the mountains".

In summary, the so-called Heilongjiang River Basin refers to the area where the entire Heilongjiang River system flows. Heilongjiang is the largest river in Northeast Asia, the sixth largest river in the world as well as the third largest river in China. The upper and middle reaches of Heilongjiang River are classified as the boundary river

*This article is the phased research result of the "Russian Far East Think Tank Special Project" of Heihe University, project number: 18YD2KCJC03. This article is the result of the phased research of Heilongjiang Province Philosophy and Social Science Project, project number: 18 YSE614. between China and Russia. The lower reaches of Khabarovsk are all Russian inland rivers.

"Solon" is the name that appeared in the late Ming and early Qing dynasties and it is an indigenous people in the Heilongjiang region. According to historical records, the socalled "Solon people" has appeared in the late Ming and early Qing dynasties, which was the collective name of several ethnic groups. There are also Daur, Oroqen and other families in the dwelling place of solon. Many scholars believe that the so-called Solon people include Ewenki, Daur and Oroqen. The Solon nation in the Sino-Russian Heilongjiang River Valley is the general name of the Ewenki, Daur and Oroqen in the Sino-Russian region where the entire Heilongjiang water system flows.

The concept of "plastic art" is limited to the narrow areas of painting, arts and crafts, architectural art, religious art and other major aspects of plastic arts.

This paper make overview on the research status of the Solon people of Heilongjiang River Valley in the SinoRussian Heilongjiang River Valley based on the plastic arts of Ewenki, Daur and Oroqen.

\section{CLASSIFICATION AND OVERVIEW OF DOMESTIC RESEARCH}

The domestic research situation in China can be roughly divided into five categories:

- The first is the academic achievements from the fields of history, anthropology, ethnology and other national subjects. Experts and scholars in this field are involved in the related issues of plastic arts of Ewenki, Daur and Oroqen in the study of ethnic history. They often use the national plastic arts as a physical illustration of historical research to illustrate the problem, but there is no discussion of plastic arts in a special academic sense. For example, New Book of Tang written by Song Yi and Ouyang Xiu in the Northern Song Dynasty, the "Tongkao" compiled by Ma Duanlin in the late Song Dynasty and the Yuan Dynasty, Ming Shilu recorded in the Ming Dynasty, and the Unity of Ming Dynasty of Han People's Official General Geography Documents, 
Shuofangbeicheng, an work on the geography written by He Qiutao in the Qing Dynasty, "Sheng Jing Tong Zhi" compiled by Agui et al. in Qing Dynasty, "Jilin Tongzhi" edited by Guo Buloo Changshun and $\mathrm{Li}$ Guilin in Qing Dynasty, "Heilongjiang Foreign Record" written by scholar Xi Qing in Qing Dynasty, the geography records of "Heilongjiang draft" compiled by Zhang Boying at al. record the history, folklore characteristics, humanities and other characteristics of ethnic minorities such as Dashang in northern China in detail. The "Plastic Art of ethnic group in Heilongjiang River Valley" published by Tianjin Ancient Books Publishing House compiled by Sun Yunlai shows the folk life of the ethnic group in Heilongjiang River Valley and its contribution to the plastic arts with rich and colorful materials for us and introduces the plastic arts into the field of Shaman culture research for the first time.

- The second is the relevant research materials written after the official investigation. From their own professional perspectives, experts and scholars have detailed records and detailed descriptions of the physical and creative process of national plastic arts. However, it focuses on the tracking of the reasons of folk culture, and stops at the exploration of aesthetics and the revealing of artistic laws. The authoritative and highly acclaimed materials in the society include the "The study on Daganer, Ewenki, and Oroqen culture" compiled by Inner Mongolia Autonomous Region Academy of Social Sciences; Chinese minority social and historical series "The social and Historical Survey on Ewenki" edited by Inner Mongolian Autonomous Region Editorial Group in 1986 is especially detailed in the introduction of the traditional culture of Ewenki. It also has a rich introduction to the traditional means of transportation of Ewenki; Chinese minority cultural book "Folktales of Three Minorities in Inner Mongolian" records a large number of ethnic religious beliefs and the collision and influence of traditional culture between ethnic groups.

- The third is the excavation report and archaeological research monograph from the archaeological circle. Due to major, experts and scholars of the archaeological circle have contributed a lot in the collection of cultural relics and excavation of tombs. For example, the accurate identify of unearthed cultural relics by using new scientific and technological means can mostly be accepted by the academic circles. It also stops at in-depth discussion of the artifacts of these ethnic groups and examination of the laws and artistic characteristics of their development.

- The fourth is academic research by individuals or non-government organization. With the interest and enthusiasm in academic research, unofficial individuals and non-government organization have become the main force in the study of traditional culture of ethnic minorities in China. They actively carried out data collection and field visits on traditional vehicles of ethnic minorities in northern China, and spontaneously organized academic seminars to promote mutual learning and exchange, and jointly enhance themselves, which can raise the attention of society to the traditional vehicles of northern minorities, develop and promote the national spirit, and inherit national culture. Among them, the studies on ethnic traditions include "Daganer's plastic art", "Document of Daganer cultural relic", "primitive art of hunting national", "folk art of Shilu tribe", and "Daganer century record" and so on. Among them, the "Document of Daganer cultural relic" describes the traditional ethnic plastic arts of Daganer from various angles, such as the type, function and art form.

- The fifth is the effort made by the colleagues of Arts Circle. They often go deep into the ethnic areas to sketch from nature, and collect the plastic arts products and historical relics of some ethnic groups for the needs of creation and appreciation. However, their focus is on the imitation and reference of actual artistic creation. The style characteristics and aesthetic pursuit of national plastic art in Heilongjiang River Valley are presented indirectly and dispersedly in painting, sculpture, and craft products through the formal language of artistic creation, rather than being elaborated academically.

\section{OVERVIEW OF FOREIGN RESEARCH}

On the one hand, foreign studies focused on the historical study of the northern nomadic peoples. From the 1920 s to the 1930s, Japanese scholars such as Jian Nei Gen and Bainiao Kuji began to make field surveys and case studies on the history and culture of the nomadic peoples in northern China. They have published academic monographs such as "Mongolian History Research" and "Donghu Nationality Investigation"; Russians are not far behind in the study of the history and culture of nomadic people in northern China. From the beginning of 1892 to the end of the following year, Russian traveler Ama. Pozdnyev (18511920) conducted field investigation of the Mongolian Plateau and wrote the material of field investigation into diary style the Mongolia and Mongolian. The Russian scholars has put a lot of energy and time into the study of architecture art of this prairie city to measure the city wall of imperial city, take a lot of photos of the remnant steles in the imperial city and make rubbings, leaving us the precious first-hand field study materials to study the architectural art of nomadic people in northern China.

On the other hand, Western scholars pay attention to the plastic art of nomadic people in the north of China. As far as academic research is concerned, it is reflected in the following academic monographs, such as the book "Historical Materials of Western Turkic" written by French scholar Sha Wan, which was translated by Feng Chengyu and published in the next year. In addition, the books that haven't been translated into Chinese include Borovka G.'s 
"Scythia Art", which is a systematic study of the ancient Scythian art of Central Asia and West Asia by Western scholars. Herm berg. U. made a profound analysis of the costumes and meanings of the shamans in northern China in his book "Shaman's Costumes and Their Significance", which involves the hunting culture of the mountain nation of Gusi language ethnic group of Altai language system and the nomadic culture of the Mongolian language family in the Altaic language. Then, until the beginning of the last century, the research on the plastic art of the nomadic nomads in Central Asia and West Asia continued to develop. There were "Art of Northern Nomadic nations", "The Ethnic Group of Central Asia", and "Mongolian - social organizations of Tujue prairie nomadic people" published. By the middle and late 20th century, the study of the culture and art of nomadic peoples in Central Asia and Northeast Asia has once again become a hot topic, including the nomadic people in northern China. We list some of the representative academic research monographs as follows: The Art of the Felt Maker (Burkett, M. Kendal, 1979) and "The Nomads and the Outside World" (Khazanov, AM., Csmbridge, London etc., 1984.) are monographs. The special researches include GRIDLEY, MARILYN LEIDIG's doctoral thesis "Buddhist Sculpture in Chinese Liao Dynasty" published by the University of Kansas Press, and Robert Albrght Rorex's The story of Wenji of the nomadic people in the murals of Liao Tomb and Chinese paintings.

In summary, most of the scholars' researches focus on the study of the history of northern minorities and only have a general statement about the plastic arts. There are clear deficiencies in the depth of theoretical exploration and the highlighting of academic personality. For the study related to national plastic arts, experts and scholars at home and abroad have compiled a large amount of literature and materials, and demonstrated from different angles. There are results in form of special research papers and academic monographs. However, they are mostly limited to the study of individual cases or the research in a particular subject area. The researches deeply excavating the national plastic art from the perspective of aesthetics are scattered, and there is still blank in the art research especially for the local ethnic groups with regional characteristics, namely Solon people in the Sino-Russian Heilongjiang River Valley. This research is a preliminary attempt and exploration in this field.

\section{The VAlue OF THE RESEARCH ON THE Status QuO OF THE SOLON PEOPLE PLASTIC ART IN THE HEILONGJIANG RIVER VALLEY BETWEEN CHINA AND RUSSIA}

Most of the scholars' researches focus on the study of the history of northern minorities and only have a general statement about the plastic arts. There are clear deficiencies in the depth of theoretical exploration and the highlighting of academic personality. For the study related to national plastic arts, experts and scholars at home and abroad have compiled a large amount of literature and materials, and demonstrated from different angles. There are results in form of special research papers and academic monographs. However, they are mostly limited to the study of individual cases or the research in a particular subject area. The researches deeply excavating the national plastic art from the perspective of aesthetics are scattered, and there is still blank in the art research especially for the local ethnic groups with regional characteristics, namely Solon people in the Sino-Russian Heilongjiang River Valley. This research is a preliminary attempt and exploration in this field.

The author conducts a systematic study on the plastic arts of Solon tribe in Heilongjiang River Valley between China and Russia. Through the aesthetic perspective, the Solon tribe modeling art in the Heilongjiang Valley of China and Russia is deeply studied, and a perfect aesthetic database of plastic arts of Solon tribe in Heilongjiang River Valley between China and Russia is formed, which lays the foundation for the study of the national culture of the Heilongjiang River Valley in China and Russia. This research involves the study of Chinese and Russian national plastic arts, and mines the national art cultural heritage in Heilongjiang River Valley. It will be an important way to study the occurrence and development of the Heilongjiang River Valley civilization, and make a positive and important contribution to the interaction of Eastern and Western civilizations in Eurasia. Through this study, the unique Solon tribal art in Heilongjiang River Valley was included into the study of Heilongjiang River Valley culture, filling the gaps and blank in the research field of national culture and history in Heilongjiang River Valley from an aesthetic perspective, and providing academic basis for the comprehensive study of the national culture of Heilongjiang River Valley. This research lays a theoretical foundation for the study of Chinese minority culture and art research. At the same time, it explores the national art and cultural heritage of Heilongjiang River Valley. The inheritance and development of this plastic art will not only help to improve the spirit of the minority people in Heilongjiang River Valley and promote culture development and construction, but also can inspire the inheritance and protection of local ethnic culture and play a positive role in enriching and developing the Chinese national culture. Through this research, the characteristics and cultural connotation of national plastic arts in Heilongjiang River Valley are deeply explored, and its unique national art connotation is applied to the creation and form expression of national art theme, which is of great significance to inheriting and promoting regional national culture, promoting regional national art, and exploring the depth of contemporary artistic creation.

\section{CONCLUSION}

- The aesthetic database of plastic arts research of Solon tribe in Heilongjiang River Valley formed in the project research will be directly applied to the academic research of Heilongjiang River Valley culture, and exert its important research value in the field of art research, when filling the academic blanks of aesthetic research in this field.

- Carrying out research on the Solon tribe's plastic arts in Heilongjiang River Valley through the project is conducive to promoting regional economic and trade development and mutual benefit, and promoting the 
development and prosperity of the national and regional culture and art, thus establishing the discipline direction of the art regional motherhood in the new era, and building a new development orientation and goal of the academic research system of art disciplines in local colleges and universities.

In order to create a new scientific direction with the research characteristics of "Ancient national plastic arts in Heilongjiang River Valley in China, Russia and Mongolia", the author exploits new idea and new path for the study to make School of Fine Arts and Design seek new development directions in the discipline construction and development.

\section{REFERENCES}

[1] Sun Yunlai tr. "The plastic arts of the nationalities in Heilongjiang River Valley", [M] Tianjin Ancient Books Publishing House, 1990.

[2] Song Guoqiu, Research on the plastic art of the northern ethnic group Shaman [D] Harbin University of Science and Technology, 2012.

[3] Liu Xin, Research on the plastic art and its inheritance of traditional Chinese vehicles in Northern China, [D] Inner Mongolia Agricultural University, 2016.

[4] Li Yong, Cultural inheritance and protection of traditional plastic arts of regional minorities [J], Gansu Social Sciences, 2010. 